\title{
Influenced Global Consumption Orientation impacts Global Brand Attitude with reference to Indian Consumers' perspective?
}

\author{
Sathyanarayan. $\mathrm{K}^{1}$, Sugavanam K.R. ${ }^{2}$ \\ \{sathyanarayan2k2001@yahoo.co.in $\left.{ }^{1}, k r s 1697 @ y a h o o . c o . i n^{2}\right\}$ \\ Department of Management Studies, University of Madras ${ }^{1,2}$
}

\begin{abstract}
According to world culture theory, the process of globalization deals not only with the integration and interdependence of world systems, but potentially giving birth to a new global culture because consumers feel that world is a single place and not a group of countries. [37]. This Global Consumer Orientation (GCO) is being influenced by Mass Media exposure such as Advertisement with celebrities vouching for the products on one side and the social status given to the product by the consumer on the other side. The consumer being part of the society is influenced by the culture and in turn it impacts GCO. A key implication is that market decision makers should be aware of this group. Our study attempts to capture the details of the model developed by the authors on the basis of GCO. The sample have been decided to support the model which has independent moderator and dependent variable. The independent variables consist of media and consumption related to social factor will be predicting Global Brand attitude through Global Consumption orientation.
\end{abstract}

Keywords: GCO, Status Consumption, Culture, Communication, GBA

\section{Introduction}

Global Consumer Orientation (GCO) as Alden puts it, is the consumer behavior towards global products. It is the increased interdependence and integration of the economic, political, and social environments that have led to the emergence of what some refer to as a globally oriented consumer, or the global consumer culture [40]. According to world culture theory, the process of globalization deals not only with the integration and interdependence of world systems, but with the conceiving of the world as a single place leading potentially to the rise of a global culture[37]. This Consumer culture - and the marketplace ideology it conveys-frames consumers' horizons of conceivable action, feeling, and thought, making certain patterns of behavior and sense-making interpretations more likely than others [14]. So possibility of GCO influencing the global brand selection is on the higher side.

Eastman et al.,[13]; Bourdieu[7] define Status consumption as relating to the consumers' behaviour who would like to purchase goods and avail services thereby attain a status which the product/service give irrespective of consumers' income or social class they belong.

O'Cass and Frost [29] observed that usually status consumption means expensive products and these products are normally used during special occasion such as festivals, marriage or 
anniversary and also used during some special occasions. Consumers also use these products to mark their achievements.

People feel the possessions denote his / her level of success and make inferences through these possessions [30] [26]. Solomon [26] also expressed similar opinion that others assess the individuals based on their usage of the products (brands) and this creates a social identity for the individuals. This makes distinction among the consumers and consumers feel happy about it.

Global brand managers specifically target cosmopolitan consumers as an important segment because they consume goods which are high on cultural capital and its authenticity. So it is imperative that global brands positioned on these factors will be a huge hit with this segment. [4].

As per Steenkamp et. al.[42] in traditional or less advanced countries, the local products are not considered to be social class items and the social elite move away from these local products. They treat them as old-fashioned and not worthy of consumption. Global brand attraction is very strong for them.

Consumer Behaviour in the current globalization scenario can vary depend on the product and the value attributed to that product. There are many factors impacts this but of all social consumption, media exposure and the quality play significant roles when it is branded products. Consumers tend to buy branded products to be perceived as a social status in the society. This trend is seen now-a-days in travel also as more travelers prefer foreign destinations for their vacation even though there are a lot of un-explored destinations within India itself. This is mostly due to peer pressure from all age groups starting from children at school level to members of clubs at the senior level. Social consumption becomes a conduit to Global brand selection and this leads to a different class of consumers. Companies also started creating a separate set of advertisements for this class to enhance their business

Status consumption as a result of culture or peer pressure and other variables have been tested and analyzed. But status consumption as a controlling variable for GCO impact was not extensively studied. So we would like to embark on this study to get more insight into this aspect. The culture is being treated as a moderating variable to find out its influence on the output. Ultimately Global Brand attitude is to be analyzed in this environment.

The study will help the marketing organization to tune their advertisement campaign as well as to create /modify their product mix for this group of consumer

Objective of the study is to analyze the Global Brand attitude of the consumer in circumstances where the consumer is influenced by the society and his/her culture. The consumer's status expectation by possessing a globally acclaimed brand may drive this attitude. If we get the analysis of this aspect, the marketing can identify them as GCO consumers and there could be a need for concentrated effort for them from the company or corporate side.

With more exposure to global trends either through travel or education or knowledge acquisition by way of interaction \& media, the attitude for the global brand is changing towards positive side. The availability and accessibility also contributes to this trend. This trend is across all the ages and all class of society. The globalization which starts 25 years ago has pervaded in all aspects of life seamlessly now. The marketers need to identify this and effect a change in their 
approach towards this set of consumers. This study, in this context, assumes more significance as to ascertain whether there is change in Global Brand attitude.

\section{Literature Review}

Liu and Johnson[23] feels that if consumers perceive positively about any country then product from that country or countries will be evaluated favourably by them. They feel that those countries are economically well-developed countries. [25]

Indeed, the consumers in the developing countries are impacted by Globalization and they imitate the lifestyles of those consumers/people who live in more economically developed nations and also they follow similar consumer pattern [16]. So Globalization did give birth to a new challenge for international branded companies in finding appropriate market segments and accordingly target them with different strategies across different countries.[43]. These strategies should orient towards customer characteristics more than country specific parameters. This is due to the fact that matching customer attributes leads to successful marketing.

Steenkamp et.al.[42] commented that in the recent past Marketplace globalization has been one of the key trends happened across the world. This phenomenon diffused the borders across the countries for markets and this helped in promoting quality of the product by way of standardization of manufacturing methods, increase in awareness of the brands through media $\&$ internet, increase in investment from outside and overall improvement of quality of life. Also the travel became global and this helped in improvement of literacy level. So Globalization impacted all walks of life. This created new avenues for the companies in strategizing their offerings.

According to De Mooij, [10] individual acquire restriction and beliefs about a particular culture that have major influence upon their purchase decision. Buying behavior of consumer is determined by the cultural values[19] [21] [22]. Business can be managed appropriately in different countries and suitable plans, policies can be formed if managers have good knowledge about the culture [15][20]. According to Podrug, [36] managers face difficulty in global operations of business if they have not appropriate cultural knowledge.

As per world culture theory world is conceived as one single place and so the consumers also are forced to align themselves by constructing views or identities with respect to that world, (i.e., global or national orientation; [37]), which has implications for marketers and the strategies they employ. Personality traits will impact development of such identities

Phillip Frank et.al. [35] remarked that competition is on the higher side due to globalization and because of this all global brands are moving across the countries and are available in almost all the places across the globe. The consumers see these products as Global and the products commands uniform image and place across the world.[12]. Nevertheless, the consumers play major role in making these brands successful and acceptable. All companies who want to expand to Global market face stiff challenges to build the brand equity outside their country of present operation. That is to say when products travel in the path of LOCAL TO GLOBAL, companies need to look into different aspect from consumer aspects.

Ayşegül Özsomer et. al [4] cites that the Global brands because of globalization is getting into the center stage of the consumers when the purchase decision happens. This we can see in all places of market whether it is streets or stores or the in the media. The proliferation is so much 
that we can as the consumers see only global brands everywhere. The consumers are willing to pay a premium without much resistance, the consumers feel that the global brands give them a separate identity or sense of achievement by having those products. On one hand the global brands have its own global culture and on the other hand the consumers attribute a new meaning by adding its perceived values onto the products. This process of new meaning re-creation for the global brands adds new dimension to the market as well as to the brands.

From Supplier point of view, the global brand can impact economies of scale and create new avenues in areas such as R\&D, Marketing, production and sourcing. The global brands can be launched on new foreign markets faster than the normal launch because products need no modification for the localization [27]. Since the global brand has its set image across the globe will be benefitted in terms of developing needs and tastes in the consumers and this is because of the products has the global positioning due to its strategic appeal. [17] [32].

As Shayan Shaikh et.al [39] cites in their paper there are better and newer opportunities due to "democratization" of luxury brands on one hand but on the other hand it gives challenges in terms of developing marketing strategies for the consumers to buy the products (cited by [39]). This increases the consumption orientation in Asia and global brands are tapping this markets. As per the new trends young adults with a better income and GCO are over shadowing the middle-aged groups as Luxury product consumers. So these brands have expanded their presence and developed products to suit their income levels. ( quoted by [39])

Arpita et.al [3] states that Clothing bestows not only self-identity on to individuals but also social identity. For clothing manufacturers, it is very essential to understand how the consumers assign meaning to fashion clothing. This helps them to devise advertising strategies to target specific group. Symbolic values are being communicated by the clothing which is being endorsed by social groups.

They add that consumers' consumption as well as the purchase decisions are being influenced by the social norms and the value of a society. Consumers as individuals because of social norms tend to adapt their behaviour as per social values and systems. Also they are morally compelled to align with the behaviours and values of the group that they are part of.

Tuba Üstüner [44] is of the opinion that Global Trickle down model was propagated by many social scientists, studying Less Industrialized Countries (LIC), as a result of greater demand observed for Western Products as status symbols. This model is based on the class emulation of Simmel \& Veblen and further develops to a global scale. In the normal model the assumption always is LIC new customer emulates the upper class of their countries. But in the Global trickle down model, the emulation is according to a global social class structure. They emulate the people who are using Western Products across the globe.

Allie et. all [2] in their paper pointed out a new trend in the handbag industry has emerged. That is instead of buying the products the same branded one can he hired for rental through websites such as Avelle or bagborrowor steal.com. This makes the consumer not to spend more money for the product which is being used for a specific time period or occasion.

This trend is good from consumers' point of view as the money spent is much less and the status symbol is also being maintained. For the stores also it is profitable as the cost of the product is realized over a period and beyond that it is only profit without product being out of their hand. They can even tie up with the manufacturer to re-cycle the products. 
Michael R. Solomon[26] brings out the following points in his article. Products is the central for the exchange process as per Marketing theory as propagated by Kotler. But the marketing theorists overlook an important factor which is human behaviour towards the products wherein the product is viewed as responses rather than as cause. So concentration is on the purchase decision process rather than how consumers use the product. But in reality the product is because of inner need and to satisfy that the purchase decision is being made. The study of this will yield a lot of benefits.

1. Social scientists need to incorporate the human activities to understand the transactions as a whole.

2. Cause of behaviour in purchase decision need to be studied to understand the innovation in product usage

3. It may be possible to predict symbolic effect and to invoke needed consumer behavioural changes by restructuring the environment or product change. (E.g.: TVs, Mobiles)

4. The promotional or advertising strategies can be towards predicting or emphasizing the social role or social effect of the product rather than just material characteristics. (E.g.: Raymond advertisement: "A complete Man”)

\section{Research Gap:}

Alden et. al.[8] proposed the model for ascertaining GBA through GCO considering variables such Media Exposure (ME), susceptibility to normative influence (SNI), Mass Migration Exposure, and Materialism and consumer ethnocentrism. The model predicted positive impact of GCO on GBA and the variables except consumer ethnocentrism have positive impact on GBA. Subsequent work in acculturation suggests that prolonged intercultural contact may lead to ethno genesis - best of both i.e. best of original culture and best of emerging global one. This is a new emerging culture which has the unique elements of the global culture. Subsequent studies based on Alden model concentrated on variations of the variables suggested and sometime different output. Our model (see Fig.1) introduces SC as an independent variable for GCO in place of SNI, Materialism, and Mass Migration exposure. Also culture is treated as moderator variable in our model. 


\section{Conceptual Model}

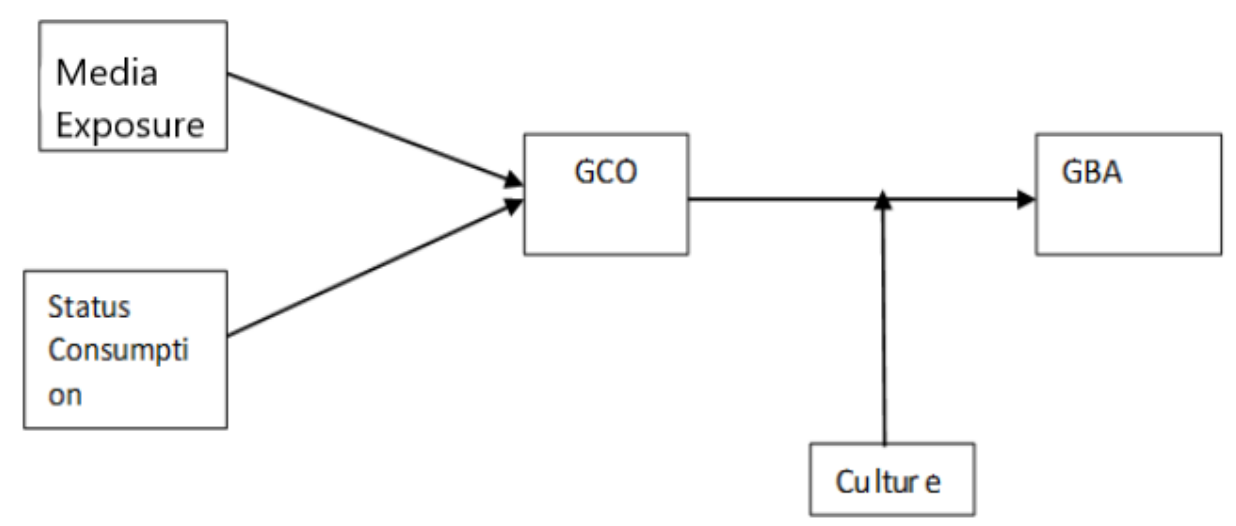

Fig.1 Conceptual Model

The Media caters to the need as well as provides information on the products \& services of different brands with celebrities as ambassadors. The consumers are being exposed to these advertisements or programs which impacts the consumption patterns of those products. This is more likely for the Global Brands. So Media Exposure was selected as one of the independent variable.

Status Consumption as mentioned earlier is to project oneself for getting better recognition. Global brands are useful in this respects as they relate themselves with the celebrities who use those products. We wanted to explore this in the Indian context given different demographic situations. This Status Consumption is the second independent variable.

Alden et al.[8]propagated GCO as an important factor for understanding Global Brand consumption and its effect on Global Brand attitude. Globalization happened in India in 1991 and more than 25 years passed after that. Now the Indian customers are well exposed to all brands either due to extensive travels across the globe or peer pressure and so awareness has improved considerably. So at this juncture we would like to ascertain the GBA of Indian Customers thru GCO.

Culture plays a very important role in Indian life. Starting from the morning coffee, Newspaper and the activities one perform during the course of the day are being influenced by the society directly or indirectly. Everyone accepts the situation consciously or as a matter of fact. For our study also we would like to see how culture is influencing GBA or GCO. So culture is being treated as moderator in this study.

\subsection{Hypotheses}

1. Consumers' Media exposure is having a positive impact on Global Consumption Orientation (GCO)

2. Consumers' Status Consumption impacts positively on GCO. 
3. Culture as a mediator influences GCO and GBA

4. Consumers' Global Brand Orientation because of SC \& ME will impact positively the Global Brand Attitude

\section{Methodology}

The questionnaire for the study was prepared based on the scale items provided by DerKarabetian and Ruiz [11], Alden, Steenkamp, and Batra [8], Appadurai[1] and they were suitably modified for the present study. Some questions were added for the variables under consideration.

Google form is used for the preparation of survey form and was shared with known friends for any understanding issues. Once that is cleared and suitable modifications done in the form, it was circulated to more known people.

Non-probability sampling was used with 105 samples and known personnel only were given the forms. The respondents were selected based on their background to ensure that understanding of the survey form is easy.

The responses were downloaded to Excel and data cleansing was done to suit SPSS needs. This is basically to code all the demographic details and the scaling details. The data were collected for all the variables such as Status Consumption (SC), Media Exposure (ME), Global Consumer Orientation (GCO), Culture and Global Brand Attitude (GBA). SC had 7 items, ME had 5 items, GCO \& Culture had 4 items and GBA had 6 items.

SPSS was used extensively to ascertain the correlation between Independent \& dependent variables. In this study GBA is the final Dependent variable and GCO is the intermediary dependent variable. SC \& ME are independent variable and Culture's effect as a moderator variable was studied. The method suggested by Brown \& Kenny was used to analyze the moderator effect of Culture on GBA

\section{Analysis}

The scale items are tested for the reliability and the results shows that Cronbach value is more than $80 \%$ which means the scale items are very reliable.

\begin{tabular}{|c|c|c|}
\hline \multicolumn{3}{|c|}{ Reliability Statistics } \\
\hline Cronbach's Alpha & $\begin{array}{c}\text { Cronbach's Alpha Based } \\
\text { on Standardized Items }\end{array}$ & N of Items \\
\hline .840 & .864 & 36 \\
\hline
\end{tabular}

Table 1: Reliability check

\subsection{Correlations}

Our intention is to find out how GBA is impacted across the model. Correlation projects the relations between the variables. 


\begin{tabular}{|cc|c|c|c|c|c|}
\hline & & GCO & GBA & SC & ME & Culture \\
\hline \multirow{2}{*}{ GCO } & Pearson Correlation & 1 & $.315^{* *}$ & $.467^{* *}$ & $.372^{* *}$ & $.254^{* *}$ \\
& Sig. (2-tailed) & & .001 & .000 & .000 & .009 \\
\hline \multirow{2}{*}{ GBA } & Pearson Correlation & $.315^{* *}$ & 1 & $.687^{* *}$ & $.291^{* *}$ & $.428^{* *}$ \\
& Sig. (2-tailed) & .001 & & .000 & .003 & .000 \\
\hline \multirow{2}{*}{ SC } & Pearson Correlation & $.467^{* *}$ & $.687^{* *}$ & 1 & $.386^{* *}$ & $.356^{* *}$ \\
& Sig. (2-tailed) & .000 & .000 & & .000 & .000 \\
\hline \multirow{2}{*}{ ME } & Pearson Correlation & $.372^{* *}$ & $.291^{* *}$ & $.386^{* *}$ & 1 & -.068 \\
& Sig. (2-tailed) & .000 & .003 & .000 & & .492 \\
\hline \multirow{2}{*}{ Culture } & Pearson Correlation & $.254^{* *}$ & $.428^{* *}$ & $.356^{* *}$ & -.068 & 1 \\
& Sig. (2-tailed) & .009 & .000 & .000 & .492 & \\
\hline
\end{tabular}

** Correlation is significant at the 0.01 level (2-tailored)

Table-2: Correlations

The table- 2 clearly shows the relationship and $\mathrm{P}$ value is less than $<.05$ except for Culture with respect to ME. It means the relation between ME and Culture is not that significant, so the culture is not affected by the media exposure in the sample we have selected. It is very interesting result in the sense the culture is very strong in this sample. All other variables are significant with respect to others. That is to say that SC and ME are significantly related to GCO. Consumers' status consumption affects the Global Consumption Orientation. The consumers are using the global brands for their status symbol. Market Exposure helps them to identify the global brands and enhances the GCO. SC has strong correlation with GCO and GBA. Also it has very good correlation with ME and Culture. This proves that $\mathrm{SC}$ is the major influencer for enhanced GBA through GCO.

On the other side, the demographic variables do not have major effect on SC except Age. The data shows that $\mathrm{SC}$ is highly effective up to the age of 40 as per the analysis. On the profession side, the self-employed/consultants and the Pvt. Sector consumers feels Global Brand enhances SC. Gender wise there was no much variation for SC.

As far as ME is concerned School students are impacted more by Media. But we can not consider this as a major find as the number of respondents is not considerable. Gender and age do not make any major difference in ME impact. In fact, ME has got less correlation with GBA indicating that Media exposure per say is not impacting greatly Global Brand attitude. 


\subsection{Impact of SC \& ME on GCO}

Impact of SC \& ME on GCO is analyzed with the available samples.

\begin{tabular}{|c|c|c|c|c|c|c|c|c|}
\hline \multicolumn{9}{|c|}{ Model Summary } \\
\hline Model & $\mathrm{R}$ & R Square & \begin{tabular}{|l} 
Adjusted R \\
Square \\
\end{tabular} & $\begin{array}{l}\text { Std. Error of } \\
\text { the Estimate }\end{array}$ & & & & \\
\hline 1 & $.511 \mathrm{a}$ & 0.262 & 0.247 & 0.7962 & & & & \\
\hline \multicolumn{9}{|c|}{ a. Predictors: (Constant), SC, ME } \\
\hline \multicolumn{9}{|c|}{$A N O V A b$} \\
\hline Model & & Sum of Squares & df & Mean Square & $\mathrm{F}$ & Sig. & & \\
\hline 1 & Regression & 22.901 & 2 & 11.450 & 18.063 & 0.000 & & \\
\hline & Residual & 64.661 & 102 & 0.634 & & & & \\
\hline & Total & 87.562 & 104 & & & & & \\
\hline \multicolumn{9}{|c|}{ a. Predictors: (Constant), SC, ME } \\
\hline \multicolumn{9}{|c|}{ b. Dependent Variable: GCO } \\
\hline \multicolumn{9}{|c|}{ Coefficients } \\
\hline \multirow[t]{2}{*}{ Model } & & $\begin{array}{c}\text { Unstandardized } \\
\text { Coefficients }\end{array}$ & & $\begin{array}{l}\text { Standardized } \\
\text { Coefficients }\end{array}$ & $\mathrm{t}$ & Sig. & \begin{tabular}{|l|} 
Collinearit \\
y Statistics
\end{tabular} & \\
\hline & & & Std. Error & Beta & & & Tolerance & VIF \\
\hline \multirow[t]{3}{*}{1} & (Constant) & -0.331 & 0.664 & & -0.499 & 0.619 & & \\
\hline & ME & 0.459 & 0.188 & 0.225 & 2.437 & 0.017 & 0.851 & 1.175 \\
\hline & $\mathrm{SC}$ & 0.491 & 0.119 & 0.381 & 4.127 & 0.000 & 0.851 & 1.175 \\
\hline \multicolumn{9}{|c|}{ a. Dependent Variable: GCO } \\
\hline \multicolumn{9}{|c|}{ Collinearity Diagnosticsa } \\
\hline \multirow[t]{2}{*}{ Model } & Dimension & Eigenvalue & Condition Index & \begin{tabular}{|c|} 
Variance \\
Proportions
\end{tabular} & & & & \\
\hline & & & & (Constant) & ME & SC & & \\
\hline \multirow[t]{3}{*}{1} & 1 & 2.964 & 1 & 0.002 & 0.001 & 0.005 & & \\
\hline & 2 & & & 0.103 & 0.049 & 0.964 & & \\
\hline & 3 & 0.007 & 20.785 & 0.895 & 0.950 & 0.031 & & \\
\hline \multicolumn{3}{|c|}{ a. Dependent Variable: GCO } & & & & & & \\
\hline
\end{tabular}

Table 3: SC \& ME Vis-à-vis GCO

Table- 3 indicates that the ME \& SC influence GCO positively. P-value is less than 0.05 which shows that model depicting ME \& SC with GCO is valid and fit. This means that the consumers will change their consumption decision due to the influence of Advertisement or any other media influence for the Global Brands. Consumers' status perception of the Brand will influence the purchase decision.

\subsection{Impact of GCO \& Culture on GBA}

In a similar way that we tested SC \& ME influence on GCO, we did the test on GCO, Culture and GBA segment separately. 


\begin{tabular}{|c|c|c|c|c|}
\hline & Correlations & GBA & GCO & Culture \\
\hline \multirow[t]{2}{*}{ GBA } & Pearson Correlation & 1 & & \\
\hline & Sig. (2-tailed) & & & \\
\hline \multirow[t]{2}{*}{ GCO } & Pearson Correlation & $.315^{* *}$ & 1 & \\
\hline & Sig. (2-tailed) & .001 & & \\
\hline \multirow[t]{2}{*}{ Culture } & Pearson Correlation & $.428^{* *}$ & $.254^{* *}$ & 1 \\
\hline & Sig. (2-tailed) & .000 & .009 & \\
\hline
\end{tabular}

Table 4: GCO , Culture with GBA

\begin{tabular}{|c|c|c|c|c|c|c|c|c|}
\hline \multicolumn{9}{|c|}{ Model Summary } \\
\hline Model & $\mathrm{R}$ & R Square & \begin{tabular}{|l|} 
Adjusted \\
R Square
\end{tabular} & \begin{tabular}{|l|} 
Std. Error of \\
the Estimate
\end{tabular} & & & & \\
\hline 1 & 0.48 & 0.23 & 0.21 & 0.73 & & & & \\
\hline a. Predi & rs: (Constant & , Culture, GCO & & & & & & \\
\hline \multicolumn{9}{|c|}{ ANOVAb } \\
\hline Model & & Sum of Squares & $\mathrm{df}$ & Mean Square & $\mathrm{F}$ & Sig. & & \\
\hline 1 & Regression & 15.92 & 2 & 7.96 & 15.13 & 0.00 & & \\
\hline & Residual & 53.66 & 102 & 0.53 & & & & \\
\hline & Total & 69.57 & 104 & & & & & \\
\hline \multicolumn{9}{|c|}{ a. Predictors: (Constant), Culture, GCO } \\
\hline \multicolumn{9}{|c|}{ b. Dependent Variable: GBA } \\
\hline \multicolumn{9}{|c|}{ Coefficientsa } \\
\hline \multirow[t]{2}{*}{ Model } & & $\begin{array}{c}\text { Unstandardized } \\
\text { Coefficients }\end{array}$ & & \begin{tabular}{|l|} 
Standardized \\
Coefficients
\end{tabular} & $\mathrm{t}$ & Sig. & $\begin{array}{l}\text { Collinearit } \\
\text { y Statistics }\end{array}$ & \\
\hline & & & Std. Error & Beta & & & Tolerance & VIF \\
\hline 1 & (Constant) & 1.31 & 0.35 & & 3.72 & 0.00 & & \\
\hline & GCO & 0.20 & 0.08 & 0.22 & 2.46 & 0.02 & 0.94 & 1.07 \\
\hline & Culture & 0.50 & 0.12 & 0.37 & 4.14 & 0.00 & 0.94 & 1.07 \\
\hline \multicolumn{9}{|c|}{ a. Dependent Variable: GBA } \\
\hline \multicolumn{9}{|c|}{ Collinearity Diagnosticsa } \\
\hline \multirow[t]{2}{*}{ Model } & Dimension & Eigenvalue & \begin{tabular}{|c|}
$\begin{array}{c}\text { Condition } \\
\text { Index }\end{array}$ \\
\end{tabular} & \begin{tabular}{|c|} 
Variance \\
Proportions \\
\end{tabular} & & & & \\
\hline & & & & (Constant) & GCO & Culture & & \\
\hline \multirow[t]{3}{*}{1} & 1 & 2.92 & 1 & 0.00 & 0.01 & 0.01 & & \\
\hline & 2 & & & 0.07 & 0.96 & 0.19 & & \\
\hline & 3 & 0.02 & 10.93 & 0.93 & 0.03 & 0.80 & & \\
\hline \multicolumn{3}{|c|}{ a. Dependent Variable: GBA } & & & & & & \\
\hline
\end{tabular}

Table 4. (Contd.) 
Table-4 provides the information on GBA with respect to GCO and Culture. From the analysis it is clear that GBA is well correlated with Culture and GCO. The p-value is less than 0.05 which means that the model depicting GCO and Culture impacting GBA is significant. GCO and Culture do influence GBA. The correlation matrix clearly points out the effect of GCO and Culture on GBA which are positive. The consumers having Global Brand Orientation are purchasing Global Brands. Culture also influencing in selecting the Global Brand. Consumers of same community try to adopt the cultural practices and in the process try to purchase the brand which community approves directly or indirectly. 


\subsection{Moderating effect of Culture}

But in this study, we were interested also in the moderating effect of culture between GCO and GBA. For this we used the method suggested by Baron and Kelly. The variables Culture, GCO and GBA are mean centered and regression was carried out with new mean centered values. Table-5 gives the result of the analysis.

\begin{tabular}{|c|c|c|c|c|c|c|c|c|}
\hline \multicolumn{9}{|c|}{ Model Summary } \\
\hline Model & $\mathrm{R}$ & R Square & \multicolumn{2}{|c|}{ Adjusted R Square } & \multicolumn{2}{|c|}{ Std. Error of the Estimate } & & \\
\hline 1 & 0.48 & 0.23 & \multicolumn{2}{|c|}{0.21} & \multicolumn{2}{|c|}{0.73} & & \\
\hline 2 & 0.49 & 0.24 & \multicolumn{2}{|c|}{0.22} & \multicolumn{2}{|c|}{0.72} & & \\
\hline \multicolumn{9}{|c|}{ a. Predictors: (Constant), Culture_c, GCO_c } \\
\hline \multicolumn{9}{|c|}{ b. Predictors: (Constant), Culture_c, GCO_c, Int2 } \\
\hline \multicolumn{9}{|c|}{ ANOVAC } \\
\hline Model & & $\begin{array}{l}\text { Sum of } \\
\text { Squares }\end{array}$ & df & Mean Square & $\mathrm{F}$ & Sig. & & \\
\hline \multirow[t]{3}{*}{1} & Regression & 15.92 & 2 & 7.96 & 15.13 & 0.00 & & \\
\hline & Residual & 53.66 & 102 & 0.53 & & & & \\
\hline & Total & 69.57 & 104 & & & & & \\
\hline \multirow[t]{3}{*}{2} & Regression & 16.55 & 3 & 5.52 & 10.51 & 0.00 & & \\
\hline & Residual & 53.02 & 101 & 0.52 & & & & \\
\hline & Total & 69.57 & 104 & & & & & \\
\hline \multicolumn{9}{|c|}{ a. Predictors: (Constant), Culture_c, GCO_c } \\
\hline \multicolumn{9}{|c|}{ b. Predictors: (Constant), Culture_c, GCO_c, Int2 } \\
\hline \multirow{2}{*}{\multicolumn{9}{|c|}{ c. Dependent Variable: GBA_c }} \\
\hline & & & & & & & & \\
\hline \multirow[t]{2}{*}{ Model } & & Beta In & $\mathrm{t}$ & Sig. & \begin{tabular}{|c|} 
Partial \\
Correlation \\
\end{tabular} & $\begin{array}{c}\text { Collinearity } \\
\text { Statistics }\end{array}$ & & \\
\hline & & & & & & Tolerance & VIF & \begin{tabular}{|l|} 
Minimum \\
Tolerance
\end{tabular} \\
\hline 1 & Int2 & 0.10 & 1.10 & 0.28 & 0.11 & 0.86 & 1.16 & 0.86 \\
\hline \multicolumn{9}{|c|}{ a. Predictors in the Model: (Constant), Culture_c, GCO_c } \\
\hline \multicolumn{9}{|c|}{ b. Dependent Variable: GBA_c } \\
\hline \multicolumn{9}{|c|}{ Collinearity Diagnosticsa } \\
\hline \multirow[t]{2}{*}{ Model } & Dimension & Eigenvalue & \begin{tabular}{|c|} 
Condition \\
Index
\end{tabular} & \begin{tabular}{|c|} 
Variance \\
Proportions \\
\end{tabular} & & & & \\
\hline & & & & (Constant) & GCO_c & Culture_c & & \\
\hline \multirow[t]{3}{*}{1} & 1 & 1.25 & 1 & 0.00 & 0.37 & 0.37 & & \\
\hline & 2 & & & & $\begin{array}{ll}0.00 \\
\end{array}$ & 0.00 & & \\
\hline & 3 & 0.75 & \begin{tabular}{|l|}
1.30 \\
\end{tabular} & 0.00 & \begin{tabular}{l|l|}
0.63 \\
\end{tabular} & 0.63 & & \\
\hline \multirow[t]{4}{*}{2} & 1 & 1.59 & 1.00 & 0.04 & \begin{tabular}{l|l|}
0.15 \\
\end{tabular} & 0.16 & & \\
\hline & 2 & 1.07 & 1.22 & 0.61 & \begin{tabular}{l|l|}
0.11 \\
\end{tabular} & 0.09 & & \\
\hline & 3 & 0.75 & 1.46 & 0.00 & 0.65 & 0.53 & & \\
\hline & 4 & 0.60 & 1.63 & 0.35 & \begin{tabular}{l|l}
0.10 \\
\end{tabular} & 0.22 & & \\
\hline \multicolumn{3}{|c|}{ a. Dependent Variable: GBA_c } & & & & & & \\
\hline
\end{tabular}

Table 5: Mean-centered analysis for GCO, Culture Vis-à-vis GBA

All variable with "_c" are mean centered variables.

From Table-5, we can observe that models with GCO_c, Culture_c and GBA_c as well as with GCO_c, Culture_c, interaction (int2) of GCO-c*Culture-c and GBA-c has p-values less than 
0.01 in the Anova test which means they are significant. So GCO and culture contribute significantly for GBA. The regression coefficients result in excluding the Int 2 variable as $\mathrm{P}$ value is 0.275 . So the model with Int2 (interaction variable), which is the moderator for GCO_c and GBA_C, is rejected.

\section{Discussion}

From the analysis, it is very clear that consumer who wants to display his /her status prefers Global Brands. This is irrespective of Gender / Age / income and type of education they have undergone. This shows that in India the globalization has effectively spread its wings across the population. Status Consumption has a very good impact on GCO as well as GBA.

This shows that Indian Customers are inclined to status consumption when the Global Brand is being consumed. These customers see these products as a status symbol and are consciously buying these to enhance their status. Interesting aspect is this is not impacted by Age/ Gender/ Income and Education. This could be due to the fact that the affordability of these Global Brand has increased either due to increasing in purchase power or price band has been within the reach of the consumers.

The marketing of these brands need to align themselves with this attitude by creating different status consumption pattern across the different age group or income group so that consumers will not see the differentiation as the same brand is being consumed. But there is a risk of losing customers when there is no differentiation. So perception of differentiation is the need of the hour even though the same brand is being consumed.

In the education field also this trend is happening in India. Regular schooling is being replaced by Home schooling or farm schooling or travel schooling and so on. These needs are being addressed by institutes by identifying the consumers or creating awareness among the consumers.

Since culture is not having a moderating effect on GBA or GCO as per our current study, it provides new clue to the marketing Managers. This is probably because of the fact that globalization helps consumers aware of all brands and ensures the availability of the brands at all places. So Marketing Managers' strategy could be working on the cosmopolitanism for effective reach of the consumers.

\section{Managerial Implications}

This study brings out one important aspect which is SC impacting GCO and GBA. Generally, SC links with Culture which is so here in our study also. But the mediating effect of culture is insignificant and so the managers need to take SC route to reach the customer. The product or services should appeal to the SC aspect of the consumers through media for enhancing GCO for better GBA. So strategy should be to make the product or services global so that the comparison is with Global Brand. Managers should highlight the Global Brandedness of the product or services to appeal to Consumers' SC for enhancing the business. This improves the overall quality of the consumers and so the society. Since the result shows that Gender-wise or income- 
wise, there is no major variation in any of the variables, Managers can work on an attractive price scheme for their product or services as the target base is larger now.

With Make India movement of Indian Government is in swing, the question in marketing managers' mind is whether Global Brand will have a market in India in the near future. The survey reveals that there is Global Brand attitude as well as Global Brand Orientation in the consumers' mind. Status Consumption strongly impacting these two parameters. So the global Brands can be made in India under the Make-India program so that affordability will not be an issue. Also the availability and serviceability will be much more and so the consumer satisfaction will be increasing. This will be a strategic decision for the company as shifting the operations should be cost-effective. This is possible only when more consumers should patronize the products. Media exposure will be handy in this situation for the managers as the reaching out to the consumers with Make-India tag will be an advantage for the organization.

Also the organization can create a social culture called Global-Made-in-India where the Global brands availability at Indian Price with better services which can moderate the GBA at a later stage.

Digitalization is the order of the day. The managers can make use of this facility for the media campaign for better publishing of their product and reach out more consumers for expanding their market base.

\section{Conclusion}

With the data and the subsequent analysis, we can conclude that GCO has a positive impact on GBA which was already stayed by Alden. But the variables we have taken here were SC \& ME which has a positive impact on GCO. All these variables have positive influence on GBA also. Culture does not have moderating effect on GCO and GBA relationship.

This is a very interesting findings in the sense, the general perception is that culture is always influences the individual or group especially in the Indian context. It has been proved in that respect also for so many years. The trend is changing because of the awareness among the consumers is better than before. Also the digital marketing helps the consumers to interact with the vendors to understand the products and also remove the inhibitions on the part of the consumers as they need not have face-to-face conversations and affected by the judgement of the sales persons.

\section{Limitation and future Research}

There are a few limitations when we conducted this study. As mentioned earlier, we could not gather more responses due to paucity of time. Data Collection by going to different locations such as Malls, colleges etc. could not be done. This could have affected the final outcome. So future study can go with a bigger sample size. Nevertheless, the present study covers fairly people from different segments such as Government, Public sector, Private Sectors, Business personnel and consultants. Also the coverage on education background is satisfactory. Future study can concentrate on a particular working segment or with specific educational background. Also researcher did not restrict the responses to one location since the forms are circulated over 
internet. Future research can work on this aspect such that it can concentrate on one location in India (could be city or town or village). This study definitely provides some clue on GBA with respect to SC, ME, GCO. This helps companies to concentrate their efforts on creating awareness of brands through SC as a means of reaching the consumers. Culture as per our study is not acting as a mediator between GCO and GBA. This can be further analyzed with a larger sample size wherein SEM also can be used to ascertain the role of Culture.

Overall the study provides an insight into Global Brand attitude of the consumers. This can be further explored taking one segment of product such as Travel or entertainment to ascertain the relationship. This is because the present generation is more into moving outside towards Global destinations either for education or vacation or both. So the combination of segment and generation also can be used for future research.

\section{References}

[1] Appadurai, A. : "Disjuncture and difference in the global cultural economy", in Featherstone, M. (Ed.), Global Culture: Nationalism, Globalization and Modernity, Sage, London, pp. 295-319 (1990)

[2] Allie S. Grotts and Tricia Widner Johnson(2013): "Millennial consumers' status consumption of handbags" Journal of Fashion Marketing and Management Vol. 17 No. 3,2013 pp. 280-293 (2013)

[3] Arpita Khare, Ankita Mishra, Ceeba Parveen and Rajlaxmi Srivastava: "Influence of consumers' susceptibility to interpersonal influence, collective self-esteem and age on fashion clothing involvement: A study on Indian consumers" - Journal of Targeting, Measurement and Analysis for Marketing Vol. 19, 3 / 4, 227-242 (2011)

[4] Ayşegül Özsomer and Selin Altaras: " Global Brand Purchase Likelihood: A Critical Synthesis and an Integrated Conceptual Framework “- Source: Journal of International Marketing, Vol. 16, No. 4, Branding in the Global Marketplace (2008), pp. 1-28 (2008)

[5] Belk, R.W. : “An exploratory assessment of situational effects in buyer behavior", Journal of Marketing Research, Vol. 11 No. 2, pp. 156-63 (1974)

[6] Belk, R.W. : "Possessions and the extended self", Journal of Consumer Research, Vol. 15 No. 2, pp. 139-68 (1988)

[7] Bourdieu, P. : "Social space and symbolic power", Sociological Theory, Vol. 7 No. 1, pp. 14-25 (1989)

[8] Dana L. Alden, Jan-Benedict E.M. Steenkamp, Rajeev Batra : “ Consumer attitudes toward marketplace globalization: Structure, antecedents and consequences" Intern. J. of Research in Marketing 23 (2006), 227-239 (2006)

[9] Dana L. Alden, Jan-Benedict E. M. Steenkamp and Rajeev Batra: "Brand Positioning Through Advertising in Asia, North America, and Europe: The Role of Global Consumer Culture" - Journal of Marketing, Vol. 63, No. 1, pp. 75-87,(1999)

[10] De Mooij, Marieke : "The Future is Predictable for International Marketers:Converging Incomes Lead to Diverging Consumer Behaviour," International Marketing Review, 17 (2), 103-13(2000)

[11] Der-Karabetian, Aghop and Yolanda Ruiz : "Affective Bicultural and Global- Human Identity Scales for Mexican-American Adolescents," Psychological Reports, 80 (April), 1027-39 (1997) 
[12] Douglas, S.P. and Craig, S.C.: "The limits of global branding: the emerging market challenge", in Jain, S.C. and David, G. (Eds), Handbook on Research in International Marketing, 2nd ed., Edward Elgar Publishing, North Hampton, MA, pp. 3-19 (2012)

[13] Eastman, J.K., Goldsmith, R.E. and Flynn, L.R.: "Status consumption in consumer behaviour: scale development and validation", Journal of Marketing Theory and Practice, Vol. 7 No. 3, pp. 41-51(1999)

[14] Eric J. Arnould and Craig J. Thompson: "Consumer Culture Theory (CCT): Twenty Years of Research" -Journal of Consumer Research, Vol. 31, No. 4 , pp. 868-882 (2005)

[15] Francesco, A.M. and Gold, B.A.- "International Organizational Behavior: Text, Cases, and Skills, 2nd edition". Upper Saddle River, New Jersey: Pearson Prentice Hall, (2005)

[16] Ger, G. and Belk, R.W.: "Cross-cultural differences in materialism", Journal of Economic Psychology, Vol. 17, pp. 55-77(1996)

[17] Hasan , Salah S and Lea P. Katsanis: "Global Market Segmentation Strategies and Trends," in Globalization of Consumer Markets: Structures and Strategies, Salah S. Hassan and Erdener Kaynak, eds. New York: International Business Press, 47-62 (1994)

[18] Hassan, Salah S., Stephen Craft, and Wael Kortam : "Understanding the New Bases for Global Market Segmentation," Journal of Consumer Marketing, 20 (5), PP 446-62 (2003) [19] Ko, H., Jung, J., Kim, J. and Shim, S.W.: "Cross-cultural differences in perceived risk of online shopping"- Journal of Interactive Advertising, 4(2), 20-29(2004)

[20] Khatri, N.: "Consequences of Power Distance Orientation in Organisations". The Journal of Business Perspective, 13(1), 1-9 (2009)

[21] Laroche, M., Yang, Z., Kim, C., \& Richard, M. O.: "How culture matters in children's purchase influence: A multi-level investigation", Journal of the Academy of Marketing Science, 35(1), 113-26 (2007)

[22] Legoherel, P., Dauce, B., Hsu, C.H.C. and Ashok, R.: "Culture, time orientation, and exploratory buying behavior" Journal of International Consumer Marketing, 21(2), 93-107 (2009)

[23] Liu, S.S. and Johnson, K.F. : "The automatic country-of-origin effects on brand judgements", Journal of Advertising, Vol. 34 No. 1, pp. 87-97 (2005)

[24] Marieke de Mooij: "Comparing dimensions of national culture for secondary analysis of consumer behavior data of different countries" -International Marketing Review Vol. 34 No. 3 pp. 444-456 (2017)

[25] Meng, J., Nasco, S.A. and Clark, T.: "Measuring country-of-origin effects in Caucasians, African-Americans and Chinese consumers for products and services", Journal of International Consumer Marketing, Vol. 20 No. 2, pp. 17-31 (2007)

[26] Michael R. Solomon: "The Role of Products as Social Stimuli: A Symbolic Interactionism Perspective"- Journal of Consumer Research, Vol. 10, No. 3, pp. 319-329 (1983)

[27] Neff, Jack : "P\&G and Unilever's Giant Headaches," Advertising Age, 70 (May), 2228 (1999)

[28] Nitin Gupta: "The impact of globalization on consumer acculturation A study of urban, educated, middle class -Indian consumers"- Asia Pacific Journal of Marketing and Logistics Vol. 24 No. 1, pp. 41-58 (2012)

[29] O'Cass, A. and Frost, H.: "Status brands: examining the effects of non-product-related brand associations on status and conspicuous consumption”, Journal of Product \& Brand Management, Vol. 11 No. 2, pp. 67-88 (2002) 
[30] Olmsted, Allan D. : "Sociology of culture -- The Social Psychology of Material Possessions: To Have Is to Be by Helga Dittmar" - Contemporary Sociology; Washington Vol. 23, Iss. 3 (1994)

[31] Orangzab,Suleman Aziz Lodhi, Muhammad Ali: "Consumer Reaction: Linking Consumer Associations and Cultural Values" Pakistan Journal of Commerce and Social Sciences, Vol. 11 (2), 720-736 (2017)

[32] Ozsomer and Bernard L. Simonin: "Marketing Program Standardization: A CrossCountry Exploration," International Journal of Research in Marketing, 21 (4), 397-419 (2004)

[33] Paurav Shukla: "Status consumption in cross-national context Socio-psychological, brand and situational antecedents" - International Marketing Review Vol. 27 No. 1, pp. 108129 (2010)

[34] Petra Riefler, Adamantios Diamantopoulos and Judy A Siguaw : "Cosmopolitan consumers as a target group for segmentation"- Journal of International Business Studies 43, 285-305 (2012)

[35] Phillip Frank and Kittichai (Tu) Watchravesringkan: "Exploring antecedents and consequences of young consumers' perceived global brand equity"- Journal of Product \& Brand Management 25/2,160-170 (2016)

[36] Podrug, N.: "Influence of National Culture on Decision-Making Style", South East European Journal of Economics \& Business, 61(1), 37-44 (2011)

[37] Robertson, Roland: "Globalization: Social Theory and Global Culture"- Sage Publications Ltd. (1992)

[38] Saiyed Wajid Ali, Swati Sudan: "Influence of Cultural Factors on Impulse Buying Tendency: A Study of Indian Consumers" -Vision 22(1) 68-77 (2018) MDI

[39] Shayan Shaikh, Aneela Malik, M.S. Akram and Ronika Chakrabarti: "Do luxury brands successfully entice consumers? The role of bandwagon effect" International Marketing Review Vol. 34 No. 4, 2017 pp. 498-513 C Emerald Publishing Limited (2017)

[40] Stanford A. Westjohn, B.S., M.B.A.: "Global consumption orientation: an investigation of antecedents and consequences" (2009)

[41] Stanford A. Westjohn, Nitish Singh and Peter Magnusson: "Responsiveness to Global and Local Consumer Culture Positioning: A Personality and Collective Identity Perspective" -Journal of International Marketing, Vol. 20, No. 1, pp. 58-73 (2012)

[42] Steenkamp, Jan-Benedict EM; de Jong, Martijn G: A Global Investigation into the Constellation of Consumer Attitudes Toward Global and Local Products - Journal of Marketing, Vol. 74, No. 6 , pp. 18-405 (2010)

[43] Steenkamp, J. B., \& Ter Hofstede, F.: "International market segmentation: Issues and perspectives", International Journal of Research in Marketing, 19(3): 185-213 (2002)

[44] Tuba Üstüner and Douglas B. Holt : "Toward a Theory of Status Consumption in Less Industrialized Countries - Journal of Consumer Research, Vol. 37, No. 1, pp. 37-56, (2010)

[45] Yundong Huang "Global consumer culture positioning (gccp): reviews and conceptual framework"-Journal of International Business Research Volume 15, Issue 1 (2016) 